\title{
A STUDY OF THE EFFECTS OF LEISURE TIME ON CHINA'S ECONOMIC GROWTH: A NEOCLASSIC GROWTH MODEL
}

\author{
XIANG WEI,* HAILIN QU, $\dagger$ and EMILY MA $\ddagger$ \\ *Center of China Leisure Economics Research, International Studies University, Beijing, P.R. China \\ $\dagger$ School of Hotel and Restaurant Administration, Oklahoma State University, Stillwater, OK, USA \\ $\ddagger$ School of Tourism, Leisure, Hotel and Sport Management, Griffith University, Nathan Campus, \\ Nathan, Queensland, Australia
}

\begin{abstract}
The aim of this study is to assess the effects of leisure time on China's long-run economic growth. Two compensation effects of leisure are introduced into the growth model to assess if leisure choice-set affects economic growth in the long term. Time series data covering 23 years (19812003) are used in the study, and a neoclassic growth model is employed to analyze the data. The result shows a weak and negative relationship between leisure time and China's long-term economic growth.
\end{abstract}

Key words: Leisure time; Economic growth; Time series analysis; Neoclassic growth model; China

\section{Introduction}

China's economy has witnessed a rapid growth since the late 1970s. For example, China's gross domestic products (GDP) increased more than 23 times from US\$710 billion in 1981 to US\$17.12 trillion in 2003 (China National Bureau of Statistics [CNBS], 2004). The growth rate of GDP per capita remained constant at $10 \%$ for the past 10 years (CNBS, 2007).

The average leisure time that people had the chance to enjoy also increased over time. The total number of official days off in China was 62 between 1978 and 1994. This number increased 56\% to 97 days in 1995. In 1996, the Chinese govern- ment adopted a "5-working-day" policy, which made the total number of official days off to 114 days. The latest adjustment of days off in China was in 2008, bringing the total number of official days off to 147 .

It has led to the question: Can increased leisure time affect economic growth? Past studies revealed that the amount of leisure time does have impact on economic growth and business cycles (Eichenbaum, Hansen, \& Singleton, 1988; Hek, 1998; Kydland \& Prescott, 1982; Ladrón-deGuevara, Ortigueira, \& Santos, 1999; Wilensky, 1961). Previous research also observed that leisure time should enter a person's utility function if economists accept a backward curve of labor sup-

Address correspondence to Hailin Qu, Ph.D., Regents Professor and William E. Davis Distinguished Chair, School of Hotel and Restaurant Administration, Oklahoma State University, Stillwater, OK 74078, USA. Tel: 405 744-6711; Fax: 405 744-6299; E-mail: h.qu@okstate.edu 
ply. This means that an individual would prefer more leisure time than additional income once his/ her average income exceeds a certain level (Wales, 1973). Strong associations were also found among leisure time, income distribution, aggregate consumption, interest rate, and economic growth. In particular, leisure time in the utility function may bring to saddle equilibrium (Ioannides \& Taub, 1992) or the possible existence of multiple growth paths (Ladrón-de-Guevara et al., 1999). Previous researchers have been creative in introducing leisure time into an economic system. Earlier studies have noted the substitution effects of leisure time on the economy, such as in the US; however, the compensation effects of leisure time seemed to have been neglected. The substitution effect is defined as the amount that one must reduce work time and income in substitution of more leisure activities (Buchanan, 1994). The compensation effect (for instance, the positive effect of sports in leisure time on a person's work efficiency) is defined as the effect that leisure activities may enhance individual efficiency and then improve aggregate output (Cavette, 1999; Walsh, 1982). In this study, we hypothesize that both of these effects could influence the relationship between leisure time and economic growth.

The purpose of this study is to analyze the impact of leisure time on economic growth. A theoretic model of neoclassic economic growth was constructed in which leisure time was entered into human capital accumulation and technology accumulation. After that, an empiric model, the VAR model, was used to test the conclusion derived from theoretic model.

\section{Literature Review}

The research on Economic Growth Theory continues to be a topic of interest in the field of macroeconomics. The main research focuses on Economic Growth Theory. A few studies have indicated that leisure time yields utility and generates production as an individual output (Becker, 1965; Gronau, 1977). Since the 1960s, many researchers have begun to analyze the relationship between education time (which belongs to leisure activity) and economic growth (Chase, 1967; Ryder, Stafford, \& Stephan, 1976). The models pro- posed usually assume that education does not affect the quality of leisure. It meant that marginal utility of leisure time is not affected by human capital (Ladrón-de-Guevara et al., 1999). The empiric observation in the 1960s was used to compare alongside the process of production activity. These studies revealed that technological evolution occurred less frequently in the process of leisure activities. Under this assumption, productivity would be improved when the time spent on education increases, because education can enhance the competence of human capital (Lucas, 1988). As a result, time spent on other leisure activities would decease because people would like to increase their income by spending more time on education and work (Ladrón-de-Guevara et al., 1999).

More recently, researchers used RAM (Representative Agent Model) of the aggregate labor market to further analyze the impact of leisure time (including specific types of leisure time) on economic growth (Hall, 1980; Ioannides \& Taub 1992; Kydland \& Prescott, 1982; Lucas \& Rapping, 1969; Mankiw, Rotenberg, \& Summers, 1985; Zhang, 1995). Some of the hypotheses in the models, however, are illogical. For example, researchers hypothesized that there is a common implicit price of leisure for all consumers (Eichenbaum, Hansen, \& Richard, 1985; Rubinstein, 1974), which is not the case in real life (Eichenbaum et al., 1988). Therefore, since the 1980s economists have been interested in addressing these fallacies and searching for new ways to analyze the impact of leisure time on economic growth. Economists found that the relationship between preference and consumption is not always linear, concluding that the equilibrium of real interest is not always continuous (Eichenbaum et al., 1985). By introducing both consumption and leisure time into utility function in order to achieve measurement uniformity, it was indicated that multiple equilibriums in the economy might exist (Ladrón-de-Guevara et al., 1999). To be specific, if we use the Cobb-Dauglass utility function ${ }^{1}$ and the intensification labor production function, the dynamic optimal economy by the planner may be either one or two inner point roots, or one outer point root (when no time is spent on education). This result is obviously different from the analysis 
when using only one signal steady-state equilibrium as in the neoclassical and endogenous economic growth models.

Research on leisure time and economic growth has reached a new height in the past 10 years. It is worth noting that Real Business Cycle (RBC) theory created a formal framework to deal with leisure time in economy. Classic RBC model assumes that technological shock, such as progress in technology, has a strong negative effect on nonworking time, such as leisure time (Kydland \& Prescott, 1982). The predictions, however, were only based on data from certain developed countries, and no such predictions have been made for the underdeveloped or developing countries. Research shows that technological shock sometimes positively affects nonproduction investment through Research and Development (R\&D). Shea (1998) found that the periodical fluctuation of input factors was partially explained by technology shock. Further, Gali (1999) used the price-sticky model, in which firms are rigid in changing prices in response to changes in the economy, in seven developed countries. He found that technical progress would lead to the decline of working time and in turn increase leisure time in the short run. Besides, aggregate output derived from demand shock has a notable negative correlation with the increase of leisure time. The same study showed that the major reason for the periodical fluctuation of economy is due to demand shock rather than technology shock.

In the above frameworks, the increase in return and sustainable growth is explained by activities such as technological shock, R\&D, and knowledge accumulation, within the working time (Barro \& Sala-i-Martin, 1992; Jones, 1995a, 1995b; Lucas, 1988; Romer, 1986, 1990). Leisure time, however, was ignored and rationalized as having similar impacts on the quality as well as the accumulation of production factors. In fact, individual activities, such as chatting, walking, snacking, and so on, are performed both in working time and leisure time. It is important to notice that leisure time has the compensation effect on individual efficiency and economic growth (Beatty \& Torbert, 2003; Maguire, 2008; Monte, 2008).

Some studies used different methods or new models to illustrate the effect of leisure time. Orti- gueira (2000) applied the term "qualified leisure" to an endogenous economic growth model. Qualified leisure refers to the leisure time that can be adjusted by human capital. It represents a certain type of compensation effect of leisure. This model is unique in that it is globally stabled and presents a single balanced growth path. Weder (2004) used the term "Conspicuous Leisure" to refer to another type of compensation effect of leisure. He revealed that an agent's utility function will be affected by his/her counterpart's amount of leisure time. By introducing this kind of externality of leisure into a growth model, he indicated that economy may converge to a saddle stable point. Conversely, Fernandez, Novales, and Ruiz (2004) suggest that the competitive equilibrium can be indeterminate for plausible values of the elasticity of intertemporal substitution of consumption. This is because public consumption and leisure cannot be separated in the utility function.

Additionally, researchers have tested some compensation effects of leisure (Beatty \& Torbert, 2003; Gould, Moore, McGuire, \& Stebbins, 2008; Lu \& Argyle, 1994; Walsh, 1982). However, few studies assessed the overall effect of leisure on economic growth (Kokoski, 1987). The specific mechanism and path of compensation effects of leisure has not been conclusive. Therefore, this study introduces the compensation effects of leisure into the paths of human capital accumulation and technology accumulation, based on Mankiw, Romer, and Weil's (1992) model. As a result, leisure time and its effects as a whole are naturally introduced into the economic growth model. Also, further empiric tests using secondary data from China were performed to verify the propositions derived from the theoretic model.

Methods

\section{Introduction of the Theoretic Model}

In this part, the authors introduce three types of leisure time and three effects resulting from leisure to establish the theoretic model.

In the present framework, the individual's leisure time is divided into three parts. The first part is called "education leisure time." It is the time used for education, training, pursuing knowledge, and skills. We use $l_{1}$ to present it. The second part 
is called "necessary leisure time" which individuals may use to get necessary relaxation and do housework. We use $l_{2}$ to represent it. The third part is called "enjoyment leisure time." It is the time used for traveling, entertaining, exercising, and other leisure activities. We use $l_{3}$ to represent it. As usual, for a representative agent, $l_{2}$ (time spent on necessary relaxation and housework) is steady and constant. However, the amount of time spent in education $\left(l_{1}\right)$ and enjoyment leisure $\left(l_{3}\right)$ varies and is subject to different period of time [i.e., $l_{1}=l_{1}(t)$ and $l_{3}=l_{3}(t)$ ]. Here $t$ represents different periods of time, normally a year (Wei, 2006).

Under this condition, the effect of leisure time was substituted into the neoclassic growth model. In addition, two compensation effects of leisure time were also identified in this study. The two compensation effects are "Advancing by Leisure" and "Learning by Leisure."

Advancing by Leisure. In addition to education time, the amount of enjoyment leisure time $\left(l_{3}\right)$ is another determinant for human capital. The formation of human capital endowment can be promoted through enjoyment of leisure activities. This is because individuals may gain more knowledge, relax themselves, and improve their intelligence in this process (Csikszentmihalyi, 1981). In this study, this process is named the "Advancing by Leisure" effect. This is especially true in a society characterized by knowledge economy. The benefit brought by healthy and positive leisure activities is remarkable; however, this is ignored by traditional human capital theory (Maguire, 2008). It should be noted that some leisure activities (especially those unhealthy or depraved activities) could harm human capital. In this situation, the enjoyment leisure time should be considered as a negative factor for human capital (Dunlop, 2006).

Learning by Leisure. The enjoyment leisure time $\left(l_{3}\right)$ has externality to the technological level as a whole. If the activities are healthy and positive (e.g., exercise, travel, exploration, and extreme sports), the individual can enhance his/her willpower and creativity (Cavette, 1999). This could inspire innovative ideas (Maguire, 2008). The creativity and the originality of the society as a whole could be improved, if all individuals participate in healthy and positive leisure activities more frequently. It may further promote the technological level of the society, either directly or through the externality of leisure indirectly (Romer, 1990; Jones, 1995a, 1998). A single individual's impact on economy, however, is weak and limited and the accumulation effect of the enjoyment leisure time could contribute to the economy by enhancing the technological level incidentally (Gould et al., 2008). In this way, the enjoyment leisure time has positive externality to the technological level. In this study, this process is named as "Learning by Leisure" effect, a similar concept like "Learning by Doing" (Romer, 1986). The externality effect of enjoyment leisure time $\left(l_{3}\right)$ to the technology; however, is different from that of capital accumulation in which the latter is endogenous within the model while the former is exogenous.

\section{Theoretic Model}

In the present framework, the effect of "Advancing by Leisure" is entered into the accumulation path of human capital; the effect of "Learning by Leisure" is entered into the accumulation path of technology. This changed the structure of dynamics in neoclassic economic growth model. Thus, the long-run growth path of per capita output with leisure is reformulated as follows:

$$
\begin{gathered}
\frac{\dot{y}}{y}=(\alpha+\beta) \frac{\dot{k}}{k}+(1-\alpha) \frac{\dot{h}}{h}+\gamma \frac{\dot{l}_{3}}{l_{3}}+\beta n \\
=(\alpha+\beta) \frac{\dot{k}}{k}+(1-\alpha)\left(\psi_{1} \dot{l}_{1}+\psi_{3} \dot{l}_{3}\right)+\gamma \frac{\dot{l}_{3}}{l_{3}}+\beta n
\end{gathered}
$$

where $k$ is the capital stock per capita; $n=\frac{\dot{L}}{L}$ is exogenous constant population growth rate; $\alpha$ and $1-\alpha$ are the elasticity of physical capital and human capital to output, respectively; $\beta$ is the elasticity of capital stock to technology level and it exists $0<\beta<1 ; \gamma$ is the elasticity of technology affected by externality of enjoyment leisure time. Here, $\gamma<1$ in that externality of the enjoyment leisure time to the technological level is decreasing return to scale. When the accumulation of leisure time, $l$, is good for the improvement of the technological 
level, we have the parameter $\gamma>0$. Conversely, $\gamma<$ $0 . \psi_{1}$ is the speed of human capital accumulation promoted by education time $\left(l_{1}\right)$ [i.e., $\frac{d \ln H}{d l_{1}}=\psi_{1}$ ]; $\psi_{3}$ is the speed of human capital accumulation promoted by enjoyment leisure time $\left(l_{3}\right)$ [i.e. $\frac{d \ln H}{d l_{3}}=$ $\psi_{3}$; The hat "•" on the variable means the increment of this variable in this year.

\section{Propositions}

Equations (1) and (2) show the theoretical model by adding leisure to the standard neoclassic growth model (Mankiw et al., 1992). This model will test the relationship between leisure and longrun economic growth including both substitution and compensation of leisure.

In equations (1) and (2), the approach of economic growth displays not only the traditional effect from physical capital and effect from "Learning by Doing" but also some new characteristics. Specifically, the dynamical impact of leisure time on economic growth leads to the following two propositions:

Proposition 1. In the economy along balanced growth path, it is appropriate to reduce the enjoyment leisure at certain level to insure an optimal economic growth rate.

According to proposition 1, education time and working time should be maintained at a relatively high level while enjoyment time has to be controlled under a moderate level. This is due to the impact from the individual's activities in leisure time on technological level and human capital level. This could explain, to some extent, why the US has acquired relatively higher economic growth than that of France or Italy, because people of the latter two countries would like to relax more (Fogel, 2000).

Proposition 2. When leisure is considered to be normal goods, active and healthy enjoyment leisure time promotes economic growth along nonbalanced path.

Here we could see a reason for civilization and morality from economic perspective. It is worthy to not only pay attention to the formal education activities but also encourage the individuals to participate in more active, instructive, and virtuous leisure activities since the human capital is shaped both by education time and enjoyment leisure time.

In sum, two kinds of externality-one is the externality of "Learning by Doing," which happens at the process of physical capital accumulation, and the other is the externality of "Advancing by Leisure" and/or "Learning by Leisure" from external enjoyment leisure time-may maintain sustainable growth of an economy.

\section{Empiric Model and Data Analysis}

The empiric model is established derived from equation (2) in the theoretic model. The general empiric model in this study is as follows:

$$
\begin{aligned}
g_{y}=\alpha & +\beta_{1} g_{k}+\beta_{2} g_{k}(-1)+\beta_{3} g_{k}(-2)+\beta_{4} g_{h}(-1) \\
& +\beta_{5} g_{h}(-2)+\beta_{6} g_{z}(-1)+\beta_{7} g_{z}(-2) \\
& +\beta_{8} g_{l}(-1)+\beta_{9} g_{l}(-2)+\ldots+\mu
\end{aligned}
$$

where

$g_{y}$ : the growth rate of output per capita;

$g_{k}$ : the growth rate of physical capital per capita;

$g_{h}$ : the growth rate of human capital per capita;

$g_{z}$ : the growth rate of enjoyment leisure time;

$g_{l}$ : the growth rate of labor force;

$\mu$ : the statistic error;

$(-1)$ and $(-2)$ means 1 and 2 lagging term.

To test whether the long-run equilibrium relationship or cointegration relationship among variables exist, the model was tested through Unit Root ADF (Augmented Dickey-Fuller) Test. $^{2}$ In this framework, the trend parameter was estimated by the utmost 2-lag test.

Secondary data sources were used in the study. The selection of data was based on data availability, reliability, sufficiency, and ability of the variable to be measured in the model. Data were mainly collected from "Statistics Yearbook of China, 1980-2004," which was published by the China National Bureau of Statistics (CNBS, 2004).

First, data were collected to evaluate the labor force, population growth rate, and economic growth rate. In this study, $L$ represents all the untrained "primitive labor force." According to Mankiw et al. (1992), the total population in the soci- 
ety is regarded as labor force $L$ and the growth rate of population is a proxy to the growth rate of labor force if: 1) every person can supply one unit labor in unit time without elasticity of labor; and 2) full employment can exit in the long run. The population growth rate is calculated based on the number of total population per year.

Second, the human capital growth rate in China is estimated based on the method proposed by Cai and Du (2003) and Song (2003). It regards the number of human capital increased every year as the human growth rate of the society. The human capital increased every year $\left(h_{t}\right)$ is equal to the number of graduates at each educational phase (people who do not accept further education, plus the number of educational years). The calculating formula is: $h_{t}=\Sigma\left(g_{i}-r_{i}\right) y_{i}$, where $g_{i}$ is the number of graduates in some phase, $r_{i}$ is the number of students recruited in some educational phase, $y_{i}$ is the number of finished educational years; concretely, 6, 9, 12, 16 represent the fixed number of educational years for primary school, middle school, high school, and university in China, respectively. Average number of years of education come from average educational year of the Chinese population who were 15 years old in 1981 , and the human capital stock for 1981-2003, which can be calculated by the formula: $\left.H_{t+1}=H_{t}+h_{t+1}\right)$ / $P_{t+1}$, where $H_{t+1}$ is the human capital stock of whole society in the next term, $H_{t}$ is the human capital stock of whole society in the current term, and $P_{t+1}$ is the level of price of the whole society. In addition, the human capital stock of the society would be decreased due to death and other reasons. The impact of death on the human capital stock could be estimated by natural mortality $\left(\delta_{t}\right)$. The natural mortality of the population at 15-64 years old is estimated at about one third of the whole society according to Song's (2003) method, much lower than China as a whole society. And the formula for computing capital stock per capita is: $h_{t+1}=h_{t}$ $\left(1-\delta t_{+1} / P_{t+1}\right.$.

Third, for the evaluation of data on the growth rate of physical capital, we used the total amount of capital established as affected by inflation rate every year. Therefore, the per capita growth rate of physical capital could be worked out using the amount of physical capital in past years.

Fourth, in terms of estimating leisure time, it is difficult to find accurate data of enjoyment leisure time. Hence, the weighed method is employed to make the estimation. Because of the positive relationship between expense and time on leisure, total number of annual national day-off is weighed by leisure expenditure per year to gauge the amount of real enjoyment leisure time.

\section{Results}

The results revealed that the original serial and the first-order difference serial of the model were both unstable. Therefore, the second-order difference of the original series was performed by ADF (Augmented Dickey-Fuller) test. The results are shown in Table 1.

From Table 1, all the variable serials are second-order integrative and uncorrelated series, which indicates that it is possible to cointegrate dependent variables and independent variables.

Based on the above estimation, the lag 1 cointegration test on the variables was fulfilled. The test results are shown in Table 2; on the 5\% level, there are four cointegrated vectors for the model because of (the value of likelihood) $2.168512<$ 3.76 (5\% critical value).

To find the global relationship between leisure time and the economic growth, the short-run fluctuation equation was done by using the VAR

Table 1

Results of ADF Test

\begin{tabular}{lcrcc}
\hline \multirow{2}{*}{ Variables } & ADF & Test & Critical & Durbin-Watson \\
$d$ Statistic & Level & Values & Stics \\
\hline$g_{y}$ & -3.406123 & $1 \%$ & -3.8877 & 1.937883 \\
& & $5 \%$ & -3.0521 & \\
& & $10 \%$ & -2.6672 & \\
$g_{k}$ & -4.261835 & $1 \%$ & -3.8877 & 2.112346 \\
& & $5 \%$ & -3.0521 & \\
& & $10 \%$ & -2.6672 & \\
$g_{h}$ & -4.784304 & $1 \%$ & -3.8877 & 1.683468 \\
& & $5 \%$ & -3.0521 & \\
& & $10 \%$ & -2.6672 & \\
$g_{z}$ & -3.182287 & $1 \%$ & -2.7057 & 1.626796 \\
& & $5 \%$ & -1.9614 & \\
$N$ & & $10 \%$ & -1.6257 & \\
$N$ & -4.501757 & $1 \%$ & -3.8572 & 2.173111 \\
& & $5 \%$ & -3.0400 & \\
\hline & & $10 \%$ & -2.6608 & \\
\hline
\end{tabular}


Table 2

Results of the Cointegration Test

\begin{tabular}{lrccc}
\hline Eigenvalue & $\begin{array}{c}\text { Likelihood } \\
\text { Ratio }\end{array}$ & $\begin{array}{c}5 \% \text { Critical } \\
\text { Value }\end{array}$ & $\begin{array}{c}\text { 1\% Critical } \\
\text { Value }\end{array}$ & $\begin{array}{c}\text { Hypothesize } \\
\text { No. of CE(s) }\end{array}$ \\
\hline 0.940771 & 121.71020 & 68.52 & 76.07 & None \\
0.728289 & 65.18328 & 47.21 & 54.46 & At most 1 \\
0.672659 & 39.12297 & 29.68 & 35.65 & At most 2 \\
0.518558 & 16.78790 & 15.41 & 20.04 & At most 3 \\
0.102754 & 2.16851 & 3.76 & 6.65 & At most 4 \\
\hline
\end{tabular}

(Vector Auto-Regression) model. After that the long-run cointegration equation was derived from the short-run equation. The VAR model is 2-lag. We excluded those variables whose lag variables failed to pass $t$-test from right side of the VAR equation. Then remaining variables were estimated by the OLS (Ordinary Lest Squares) method (see Table 3). The coefficients of $g_{h}(-1)$ and $g_{k}(-2)$ are not significant; however, the focus of the study is to assess the impact of $g_{z}(-1)$ and $g_{z}(-2)$, which are all significant in the model, and residuals were adjusted continuously to the acceptable extent (see Fig. 1). As a result, the Akaike information criterion $^{3}$ and the Schwartz criterion ${ }^{4}$ were minimized. The short-run equation based on VAR (Vector Auto-Regression) is as follows:

$$
\begin{gathered}
g_{y}=0.047808+0.526818 g_{k}+0.068553 g_{k}(-2) \\
+0.129420 g_{h}(-1)+0.040293 g_{z}(-1) \\
-0.048908 g_{z}(-2)
\end{gathered}
$$

Table 3

Results of OLS Test

\begin{tabular}{lrcrr}
\hline Variable & Coefficient & SE & $t$-Statistic & Prob. \\
\hline C & 0.047808 & 0.026538 & 1.801480 & 0.0932 \\
GH1 & 0.129420 & 0.623382 & 0.207610 & 0.8385 \\
GK & 0.526818 & 0.072650 & 7.251464 & 0.0000 \\
GZ1 & 0.040293 & 0.018049 & 2.232442 & 0.0424 \\
GZ2 & -0.048908 & 0.020572 & -2.377457 & 0.0322 \\
GK2 & 0.068553 & 0.075072 & 0.913161 & 0.3766 \\
\hline
\end{tabular}

$R^{2}=0.865557 ;$ adjusted $R^{2}=0.817541 ; \mathrm{SE}$ of regression $=$ 0.040451 ; Sum squared residual $=0.022908$; Log likelihood $=39.34121 ;$ Durbin-Watson stat $=2.582458 ;$ Mean dependent variable $=0.1366 ;$ SD dependent variable $=$ 0.0947; Akaike info criterion $=-3.3341 ;$ Schwarz criterion $=$ $-3.0354 ; F$-statistic $=18.0266 ;$ Prob. $(F$-statistic $)=0.0000$.
Then, the long-run equilibrium equation is derived as follows:

$$
\begin{gathered}
g_{y}=0.047808+0.595371 g_{k}+0.129420 g_{h} \\
-0.008615 g_{z}
\end{gathered}
$$

The results of VAR and OLS indicated that the impact of leisure time on China's economic growth is relatively weak but significant.

Further, to study the transferring effects of the interaction between the leisure time and the economic growth, it is necessary to do a Granger Causality Test with an utmost 2-lag on the growth rate of the leisure time and the economic growth rate. The results are shown in Table 4.

As shown in Table 4, the growth rate of leisure time $\left(g_{z}\right)$ is the Granger Cause of economic growth rate $\left(g_{y}\right)$; however, $g_{y}$ is not the Granger Cause of $g_{z}$, which explains that the change of leisure time could give the reason for the variety of economic growth in China.

\section{Discussion}

Based on the results of equation (4), physical capital accumulation is an engine of the Chinese economy either in the short run or in the long run. In other words, China's economy is driven by investment. At the same time the negative relationship between leisure time and China's economic growth is significant. The change of real leisure time can cause the economy to fluctuate although the impact is not robust-impact from the rate of leisure time change on the economy is less than $1 \%$.

In terms of the leisure time, equation (3) indicates that former enjoyment leisure time makes a slight negative contribution to sequential eco- 


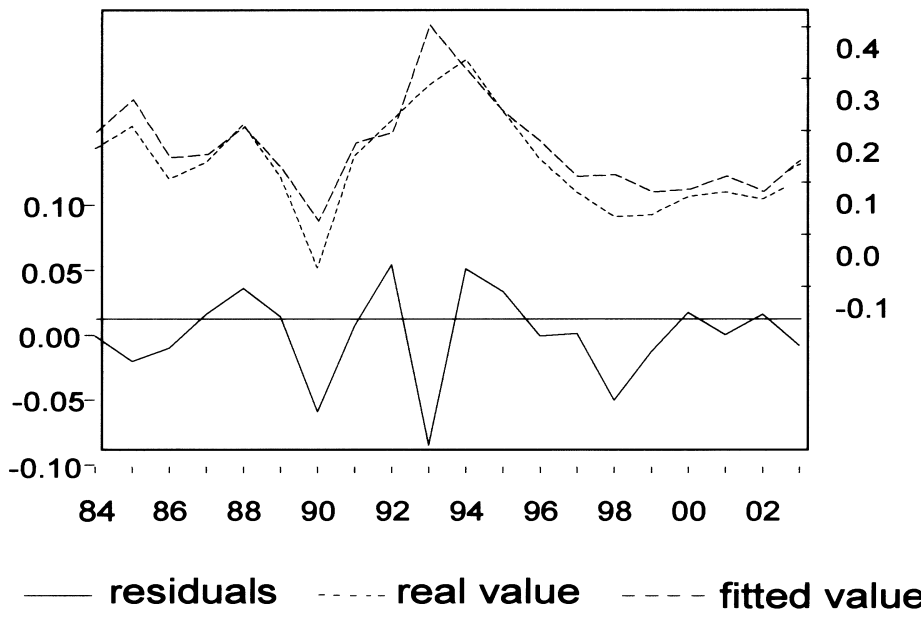

Figure 1. The residuals of VAR and OLS model.

nomic growth. The reason may be that China's economic growth is not along the balanced growth path in which the average output $(Y / K)$ fluctuates in a large range. This means that China is in the process of the industrialization.

To summarize, the real leisure time of Chinese people has increased with the implementation of "5-working-day-week" and "golden holiday week" policies. The quality of life and the social economy also improved due to increased leisure time. However, it is worth noting that China is still in the process of industrialization and is far away from being a postindustrialization society in which the positive impact from leisure on economic growth is usually stronger (Cheng \& Huang, 2003; $\mathrm{Wu}, 2005)$. Therefore, a weak but negative effect of leisure activities on the economy still restrains the economy of China today. However, learning from developed countries' experience, the establishment of a harmonious society requires the improvement of life quality, the transition from industrialized society to welfare society, diversified

Table 4

Results of Granger Causality Test

\begin{tabular}{lcc}
\hline Null Hypothesis & $F$-Value & Probability \\
\hline$g_{z}$ is not the Granger reason of $g_{y}$ & 4.6533 & 0.02678 \\
$g_{y}$ is not the Granger reason of $g_{z}$ & 0.3286 & 0.72496 \\
\hline
\end{tabular}

demand of consumption, and increased civilization (Cheng \& Huang, 2003; Cheng \& Wu, 2007; Luo, 2008; Wu, 2005). All these indicate that the impact of leisure on economy would be strengthened. The positive effects of leisure such as "Advancing by Leisure" and "Learning by Leisure" would surpass the negative effects and bring the economy into the state of abundant wealthy as well as abundant leisure in the future. Such a developing way of postindustrialized society has been proved partially in some developed countries in Europe and North America (Wei, 2006).

Special attention should be paid to the effect of leisure time on human capital accumulation, namely the effect of informal education and "lifelong learning" on economy. This study suggests that culture and civilization have not only had great political influence but also economical significance.

There are several practical implications from this study's results. First, the degree of the impact of leisure may be dependent on the stages of economic development. In the industrialization stage, leisure time should be controlled and arranged to a relatively moderate level. It should be noted that the requirements of leisure time in industrial economy and welfare economy is different. As the society gets to harmonious economy and welfare economy, people's consumption would gradually diversify, increasing their preference to leisure, 
and reducing the substitution effect of leisure. Thus, with the transition from industrialization to after-industrialization, leisure time levels would increase and different leisure systems should be arranged according to the phases. The effect from leisure time on the forming of human capital, the impact from informal education and "life-long learning" on economy should be an area of focus for future studies, as well as the impact from colorful and healthy leisure activities.

\section{Conclusions}

This study revealed that leisure time can affect economic growth because leisure time affects human capital accumulation by improving individual's intelligence, creativity, and learning capacity. Meanwhile, leisure time has externality to the technological level and generates "Learning by Leisure" effect similar to "Learning by Doing."

Models in this study proved that China is still working toward industrialization because investment is still the major driving force for China's economy. Leisure time had a weak negative effect on the economic growth according to the results of the empiric test by using the annual statistics of China from 1981 to 2003. Chinese people's lowlevel income during the process of industrialization and relative low preference for leisure may be the main reasons.

It is worth noting that the requirements of leisure time in the industrial economy and the service economy are different. As society becomes rich and harmonious and the service industry develops at a high speed, people's consumption would become diversified, increasing their preference to leisure consumption. Thus, with the transition from industrialization to after-industrialization, an additional study is needed to explore the effect of leisure time on economy and the social welfare.

\section{Notes}

${ }^{1}$ In economics, the Cobb'Douglas functional form of utility functions is widely used to represent the relationship of a utility to consumption. It was resulted from Cobb-Douglas production function and proposed by Knut Wicksell (1851-1926), then tested against statistical evidence by Charles Cobb and Paul Douglas in 1900-1928).

${ }^{2}$ In statistics and econometrics, an Augmented DickeyFuller test (ADF) is a test for a unit root in a time series sample. It is an augmented version of the Dickey'Fuller test for a larger and more complicated set of time series models.

${ }^{3}$ Akaike's information criterion, developed by Hirotsugu Akaike under the name of "an information criterion" (AIC) in 1971 and proposed in Akaike (1974), is a measure of the goodness of fit of an estimated statistical model.

${ }^{4}$ In statistics, the Schwarz Criterion is a criterion for model selection among a class of parametric models with different numbers of parameters.

\section{References}

Akaike, H. (1974). A new look at the statistical model identification. IEEE Transactions on Automatic Control, 19(6), 716-723.

Barro, R. J., \& Sala-i-Martin, X. (1992). Public finance in models of economic growth. Review of Economic Studies, 59, 645-661.

Becker, G. S. (1965, September). A theory of the time allocation. The Economic Journal, 493-517.

Beatty, J. E., \& Torbert, W. R. (2003). The false duality of work and leisure. Journal of Management Inquiry, 12(3), 239-255.

Buchanan J. (1994). The return to increasing returns. In J. Buchanan, \& Y. Yoon, (Eds.), The return to increasing returns. Ann Arbor: The University of Michigan Press.

Cai, F., \& Du, Y. (2003). Destroying of 'Culture Revolution' on physical capital and human capital. China Quarterly of Economics, 2(4), 795-806.

Cavette, K. L. (1999). Demographic, environmental, social and organizational effects of employee's leisure activity preferences and satisfaction. Ph.D. dissertation, University of Mississippi.

Chase, E. S. (1967). Leisure and consumption. In K. Shell (Ed.), Essays on the theory of optimal economic growth. Cambridge: MIT Press.

Cheng, J., \& Huang, Q. (2003). Indicators and assessment of industrial modernization and a preliminary evaluation of China's industry. Social Sciences in China, A bimonthly, 3(5), 35-56.

Cheng, J. H., \& Wu, Q. S. (2007). Environment issues in China's industrialization and the model of "Endogenous Environment Cost." Management World, 1, 33-61.

China National Bureau of Statistics. (2004). Statistics yearbook of China. Beijing: Author.

China National Bureau of Statistics. (2007). Statistics yearbook of China. Beijing: Author.

Csikszentmihalyi, M. (1981). Leisure and socialization. Social Forces, 60, 332-40.

Dunlop, P. M. (2006). Active employees! Exploring the relationship between job characteristics, perceived constraints and participation in leisure-time physical activity. Thesis, University of North Carolina at Chapel Hill.

Eichenbaum, S. M., Hansen, L. P., \& Richard, S. F. (1985). The dynamic equilibrium pricing of durable consumption goods. Manuscript, Carnegie-Mellon University.

Eichenbaum, M. S., Hansen, L. P., \& Singleton, K. J. (1988). A time series analysis of representative agent 
models of consumption and leisure choice under uncertainty. The Quarterly Journal of Economics, 2, 51-78.

Fernandez, E., Novales, A., \& Ruiz, J. (2004). Indeterminacy under non-separability of public consumption and leisure in the utility function. Economic Modeling, 21(3), 409-28.

Fogel, R. W. (2000). The fourth great awaken and the future of egalitarianism. Chicago: University of Chicago Press.

Gali, J. (1999). Technology, employment and the business cycle: Do technology shocks explain aggregate fluctuation? American Economic Review, 89(1), 249-271.

Gould, J., Moore, D., McGuire, F., \& Stebbins, R. (2008). Development of the serious leisure inventory and measurement. Journal of Leisure Research, 40(1), 47-68.

Gronau, R. (1977). Leisure, home production and work: The theory of the allocation of time revisited. Journal of Political Economics, 85(6), 1099-1123.

Hall, R. E. (1980). Labor supply and aggregate fluctuation. In K. Brunner \& A. Meltzer (Ed.), On the state of macroeconomics, Carnegie-Rochester Conference on Public Policy[C], XII. Amsterdam: North-Holland.

Hek, P. A. (1998). An aggregative model of capital accumulation with leisure-dependent utility. Journal of Economic Dynamics and Control, 23, 255-76.

Ioannides, Y. M., \& Taub, B. (1992). On dynamics with time-to-build investment technology and non-timeseparable leisure. Journal of Economic Dynamics and Control, 16, 225-41.

Jones, C. I. (1995a). R\&D-based modeled of economic growth. Journal of Political Economy, 103, 759-784.

Jones, C. I. (1995b). Time series tests of endogenous growth models. Quarterly Journal of Economics, $110(2), 495-525$.

Jones, C. I. (1998). Introduction to economic growth. New York: W. W. Norton \& Company, Inc.

Kydland, F. E., \& Prescott, E. C. (1982). Time to build and aggregate fluctuations. Econometrica, L, 1345-1370.

Ladrón-de-Guevara, A., Ortigueira, S., \& Santos, M. S. (1999). A two-sector model of endogenous growth with leisure. Review of Economic Studies, 66, 609-631.

Lu, L., \& Argyle, M. (1994). Leisure satisfaction and happiness as a function of leisure activity. The Kaohsiung Journal Of Medical Sciences, 10(2), 89-96.

Lucas, R. E. (1988). On the mechanism of economic development. Journal of Monetary Economics, 22, 3-42.

Lucas, R. E., \& Rapping, L. A. (1969). Real wages, employment and inflation. Journal of Political Economics, LXXVII, 721-754.

Luo, Z. (2008). A summary review of relationship between industrialization and urban migrant workers in China. Southern Economy, 7, 33-43.

Maguire, J. S. (2008). Leisure and obligation of self-work: An examination of the fitness field. Leisure Studies, 27(1), 59-75.

Mankiw, N. G., Romer, D., \& Weil, D. N. (1992). A contribution to the empirics of economic growth. Quarterly Journal of Economics, 107(2), 407-437.

Mankiw, N. G., Rotenberg, J., \& Summers, L. H. (1985). Intertemporal institution in macroeconomics. Quarterly Journal of Economics, C, 225-252.

Monte, R. N. (2008). Leisure participation and satisfaction for healthy lifestyles. Asia Life Science, Suppl. 2, 29-39.

Ortigueira, S. (2000). A dynamic analysis of an endogenous growth. Economic Theory, 16, 43-62.

Romer, P. M. (1986). Increasing returns and long run growth. Journal of Political Economy, 94(5), 10021037.

Romer, P. M. (1990). Capital, labor and productivity. Brookings Papers on Economic Review Papers on Economy, 98(5), 71-102.

Rubinstein, M. (1974). An aggregation theorem for securities market. Journal of Financial Economies, I, 225244.

Ryder, H. E., Stafford, F. P., \& Stephan, P. E. (1976). Labor, leisure and training over the life cycle. International Economic Review, 17, 651-674.

Shea, J. (1998). What do technology shocks do? NBER Macroeconomics Annual, 13, 275-310.

Song, G. H. (2003). The contribution of different education level to China's economic growth. Science of Finance and Economics, China, 1, 34-42.

Wales, T. J. (1973). Estimation of a labor supply curve for self-employed business proprietors. International Economic Review, 14(1), 69-80.

Walsh, E. R. (1982). Work, leisure and the pursuit of happiness. Leisure Information Newsletter Summer, 9(1), $10-11$.

Weder, M. (2004). A note on conspicuous leisure, animal spirits and endogenous cycles. Portuguese Economic Journal, 3(1), 1-13.

Wei, X. (2006). Leisure time and economic efficiency-evidence from OECD member countries. Nankai Economic Research, 12, 1-12.

Wilensky, H. L. (1961). Uneven distribute of leisure on growth: The impact of economic growth on 'free time.' Social Problems, 9(1), 32-56.

$\mathrm{Wu}$, J. L. (2005). Reflection and response: Choosing the way to Chinese industrialization (Part I). Academics Monthly, 12, 34-50.

Zhang, W. B., (1995). Leisure time, savings and trade patterns-a two-country growth model. Economic Modeling, 12(4), 425-34. 